\title{
Exenatide Stimulates Hippocampal Autophagic Activity in Alzeheimer Rat Model
}

\author{
Eman Abdo ${ }^{1}$, Mohamed Saad ${ }^{1}$, Alaa El-Din Firgany ${ }^{1}$, Youssef $\operatorname{mosaad}^{1}$, and Sara \\ Eldusoky ${ }^{1}$
}

${ }^{1}$ Mansoura University Faculty of Medicine

June 15,2020

\begin{abstract}
Purpose: This study was designed to demonstrate potential neuroprotective and autophagic activity of exenatide in rodent AD model. Experimental Approach: Thirty adult Sprague-Dawley male rats were divided into 3 groups (10 rats each); Group 1; control normal group, Group 2; AD pathological group, Group 3; exenatide treated group. All drugs were given intraperitoneal (IP) for 42 days. Behavioral changes using Morris water maze test has been evaluated, gene expressions of beclin-1 and the mammalian target of rapamycin (mTOR) in the hippocampus were assessed. Examination of hippocampal tissue using hematoxylin \& eosin (H\&E) stain and ultrastructural analyses were also done. Data were analyzed by using the statistical package for the social sciences (SPSS). Key Results: Exenatide alleviated both behavioral and pathological changes compared to pathological group. Exenatide treated group was found to improve autophagic activity by increasing beclin- 1 and decreasing mTOR gene expression. Exenatide treatment significantly prevented hippocampal neuronal degeneration demonstrated by H\&E. Moreover, accumulation of autophagic vacuoles in ultrastructure study of hippocampus, alleviated in exenatide group compared to pathological group indicating enhanced autophagic activity by exenatide. Conclusion and Implications: The results of the present study clearly indicated exenatide might have beneficial effects on impaired cognitive performance and hippocampal neuronal viability in AD by increasing autophagic activity. Increased beclin- 1 seems to be the initiating player in this disease modifying effect and this supports the assumption of a disease modifying activity of exenatide through the autophagic activity.
\end{abstract}

\section{Hosted file}

Exenatide in Alzeheimer Rat Model..docx available at https://authorea.com/users/328638/ articles/459694-exenatide-stimulates-hippocampal-autophagic-activity-in-alzeheimer-ratmodel

\section{Hosted file}

List of figures.docx available at https://authorea.com/users/328638/articles/459694exenatide-stimulates-hippocampal-autophagic-activity-in-alzeheimer-rat-model

\section{Hosted file}

List of tables.docx available at https://authorea.com/users/328638/articles/459694-exenatidestimulates-hippocampal-autophagic-activity-in-alzeheimer-rat-model 